\title{
Evaluation of a beef growth model for use in beef finishing decisions
}

\author{
M.D. ROLLO, D.G. MECALL, C.J. BOOM and G.W. SHEATH \\ AgResearch, Whatawhata Research Centre, PB 3089. Hamilton
}

\begin{abstract}
A decision support computer program for beef finishing, called BoVision, is described. It is based on biological models of animal and pasture growth, and is designed to assist the user in making strategic and tactical decisions about their beef finishing operation. Examples of its uses are to answer questions regarding profitability of 1-year versus 2-year-old cattle policies, the optimum stocking rate, and the profitability of local trade versus prime versus bull beef. BoVision can also be used to evaluate premiums required for out-of-season beef, the economics of nitrogen use and supplementary feeding. It can also be used to perform sensitivity analyses. An important aspect of the program's development process was the involvement of a group of beef finishing farmers. The animal growth and pasture intake models used are presented. This paper backgrounds the program's development, and evaluates its use in predicting Angus steer performance for a trial conducted at Whatawhata Research Centre. Performance for a Friesian bull trial is also evaluated. Implications for BoVision's use on farms are discussed.
\end{abstract}

Keywords: animal growth, beef finishing, computer model

\section{Introduction}

BoVision was developed following a series of field-day presentations (McCall 1989, 1992). These dealt with calculations on beef finishing decisions, e.g., stocking rate and purchase price. A computer program, BoVision, was written to model a beef finishing operation, which would perform these calculations. An essential part of the development process was the involvement at the design and testing stages of a group of beef finishing farmers.

This paper describes BoVision, the animal growth model that drives it, and its performance modelling two grazing trials. Input requirements, and outputs, are detailed, and some of the analyses possible with BoVision are mentioned. Details of the animal growth and intake models are then examined. Lastly, application of BoVision to two beef trials is reported.

\section{Specifications}

The program was developed using Turbo Pascal, and runs on IBM PC compatible computers. A graphic interface, with pull-down menus, dialogue boxes and spreadsheet-like data entry cells have ensured that the program is easy to learn, and intuitive to use. The involvement of a group of target users has ensured BoVision's ease of use, and relevance to beef farmers.

\section{Required input}

BoVision operates by modelling the pasture and animal components of a beef finishing operation. It requires the user to enter information specifying details of their operation in the form of policies to be analysed. A set of policies and associated information constitutes a farm and this information is saved by the program into a file on the computer's disk.

A BoVision policy contains purchase, sale, supplemental feeding, nitrogen, pasture growth, costs and schedule price information. Purchase information details time of purchase, and the number, breed, weight, sex and cost of animals purchased. Sale information specifies timing, number, carcass weight, drafting information, and how the animals were sold (e.g., schedule or store). Supplemental feeding, and application of nitrogen fertiliser, require the user to specify time and quantities. For nitrogen, area and expected response are also required. Monthly pasture growth information can be selected from a regional list, or entered directly by the user. The user can specify associated costs, and schedule prices, which can be saved and retrieved for later use. A feature of BoVision is a calibration process which uses information entered by the user, to tune the model to their current operation.

\section{Output and possible analyses}

BoVision has two distinct modes of operation. Strategic decisions are modelled in "Long-term" mode, in which the performance of a given policy (under equilibrium conditions) is assessed. Tactical decisions are modelled in "Short-term" mode, which takes specified start conditions (pasture height, number of animals on hand and their liveweight) and runs a policy for one year only. Short-term mode would bc used for a feed budget analysis.

With BoVision it is possible to analyse the effect of policy changes such as breed changes, purchase weight 
arid finishing period, and stocking rate decisions on both biological and financial performance. It is also possible to answer questions like "what premium is required to make it worthwhile keeping some of my 2year-old animals over winter, instead of selling them all in autumn?" Selling strategies can also be assessed. BoVision is essentially a calculator which allows the user to investigate quantitatively the effects of policy changes, and outcomes of competing short-term options.

Output from BoVision is presented in tabular form, and graphically where appropriate, e.g., pasture cover, supply and demand, and animal liveweights. Biological quantities (pasture and animal) and financial breakdowns of performance are output. Policy performance is measured in terms of overall margin (sale returns-costs), and most results are presented as a comparison between two policies. The program allows further flexibility by letting the user carry out sensitivity analyses. These investigate the effect of changing a particular aspect of a policy on its overall margin. It is possible to carry out sensitivity analyses on profitability for schedule prices, purchase liveweight, purchase price, and number of animals purchased, i.e., stocking rate.

\section{Model description}

The animal model used in BoVision is based on Parks' (1982) equations of animal growth. A pasture model is also incorporated (Marshall et al. 199 1), and works by dividing pasture mass into three pools, green leaf, stem and dead, and modelling the flow of pasture between these pools.

The Parks equation is derived from a simple energy balance equation, relating energy intake (food) by the animal, to its requirements for maintenance and growth.

(food $=$ maintenance + growth $)$

$$
f=\frac{1}{T_{0}} W+\frac{1}{A B} \frac{d W}{d t}
$$

It is possible to solve the above equation and relate weight at a given time to the weight at the previous time step, t.l, and the food consumed during the time period, yielding

$$
W_{t}=\left(T_{0} f-W_{t-1}\right)\left(1 \quad \exp \left(-(A B) / T_{0}\right)\right)+W_{t-1}
$$

where $T_{0}$ is a maintenance parameter (days)

$A B$ is the efficiency of growth for food above maintenance

$f$ is (daily) rate of food intake (kg DM or MJ ME per day)

$W_{t}$ is animal live weight at time $\mathrm{t}(\mathrm{kg})$
The interpretation of $T_{0}$ is the length of time $1 \mathrm{~kg}$ of liveweight is maintained by $1 \mathrm{~kg}$ of food intake. $A B$ can be interpreted as the amount of liveweight gain derived from 1 unit of food. Parks (1982) presents evidence suggesting that $A B$ is approximately constant across species, and we make the assumption that $A B$ has the constant value 0.025 . The parameter values $\left(T_{0}\right)$ were scaled by mature weight (Taylor 1980) to give a constant estimate for the maintenance parameter across breed and sex of animals.

Changes were made to the model to predict seasonal influences which appear to exist in maintenance requirements, i.e., the value of $T_{0}$ changes with season. The model uses the intake model reported by McCall et al. (1986). Potential intake was calculated as a function of animal metabolic age as follows

$$
I=\left(a-b r^{t / A}\right) A^{0.73}
$$

where I is intake ( $\mathrm{kg} \mathrm{DM} / \mathrm{hd})$

A is mature weight of the animal $(\mathrm{kg})$

$t \quad$ is animal age (weeks)

$t / A^{0.27}$ is the metabolic age of the animal

$a, b, r$ are parameters

Equation 3 uses Taylor's mature weight scaling rules (Taylor 1980) to calculate potential intake across breed and sex.

\section{Methods}

The model was used to simulate 2 years of results from the Friesian bull beef trial reported by Weeda \& During (1975), and a farmlet trial conducted at Whatawhata, involving 1-year vs 2-year-old Angus steers on two winter feeding regimes (Sheath \& Boom, unpublished).

For the Whatawhata trial, pre- and post-grazing mass, and stocking density for each break were available. Predicted intakes were compared with actual intake values assessed on the trial, and then used to supply daily food intake values $(f)$ to the Parks' model. This provided a test of the intake and animal growth models. Actual intake values were calculated from the pre- minus post-grazing mass difference, with expected pasture growth added, divided by the stocking density over the period grazed. For the Weeda \& During trial, we used average intakes reported every 90 days, and tested the animal model with respect to these intakes.

An important feature of BoVision is a calibration facility which allows for the adjustment of pasture growth estimates, and animal intake values, giving the model the flexibility required to deal with animals of varying efficiencies. This allows BoVision to be tuned to a 
particular farming situation. Using one set of intake equations assumes all animals harvest pasture with a certain efficiency, irrespective of pasture type. In order to deal with variation in grazing efficiencies, and to improve estimates of pasture growth rates on specific farms, we adjust the $k$ parameter in the intake model of McCall et al. (1986), and pasture growth rates. This adjustment procedure is automated in BoVision.

\section{Results}

A comparison of predicted results (running the model with the standard parameter values) with actual results were recorded from each trial. The calibration process was also used for the Whatawhata trial, allowing a comparison of calibrated results with predicted and actual values. Intake and liveweight values were compared for Whatawhata.

For the Friesian bull trial reported by Weeda \& During, year 1 predictions were very close to actual liveweights, whereas in year 2 predicted liveweight lagged behind actual, most notably over summer (Figure 1).

The predicted intakes for Whatawhata are generally less than actual intakes, the greatest differences being in summer and autumn, when intakes measured in the trial were very high (Table 1). Animal intakes in year 2 (at low pasture masses) were much higher than we predicted. Inspection of Table 1 indicates that the calibration generally moved the calculated intake toward the assessed intake value (year
Figure 1 Actual and predicted LWTs for Friesian bulls (Weeda \& During 1975) - two years of data.

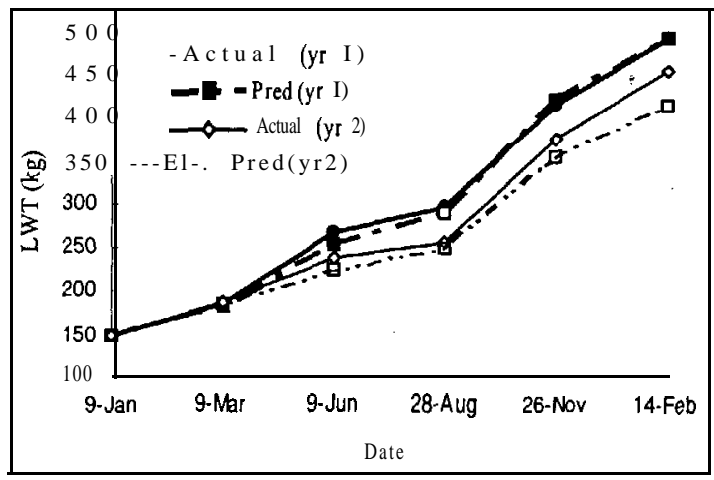

Table 1 Actual (Act), predicted (Pre) and calibrated (Cal) intakes (kg DM/hd/day) for Angus steers at Whatawhata, over 2 years.

\begin{tabular}{lcccccccccccc}
\hline & \multicolumn{2}{c}{ Winter } & \multicolumn{2}{c}{ Spring } & \multicolumn{2}{c}{ Summer } & \multicolumn{3}{c}{ Autumn } \\
Animals & Act Pre Cal & Act & Pre Cal & Act & Pre Cal & \multicolumn{2}{c}{ Act } & Pre Cal \\
\hline Year 1 & & & & & & & & & & & & \\
lyr old & 5.5 & 5.0 & & 6.6 & 6.6 & 10.7 & 8.9 & & 6.1 & 7.6 & \\
2yr old & 8.0 & 6.9 & & 11.1 & 9.6 & & 14.6 & 10.6 & & 12.7 & 9.6 & \\
Year 2 & & & & & & & & & & & & \\
lyr old & 6.0 & 4.1 & 4.1 & 7.5 & 5.3 & 8.1 & 8.3 & 7.1 & 0.5 & 9.1 & 5.0 & 3.1 \\
2yr old & 7.6 & 6.3 & 7.1 & 13.3 & 8.7 & 11.0 & 12.8 & 9.2 & 10.6 & 13.6 & 7.1 & 11.6 \\
\hline
\end{tabular}

1 calibrated intakes omitted for clarity of the table). Examination of the liveweight graphs (Figures 2 and 3) indicate a good tit for the first year; with a divergence in the second year, most notably from spring onward. This is linked to the low intake predictions. The effect of the calibration process in improving the tit is well illustrated in Figure 3.

Figure 2 Whatawhata Angus steers, year 1.

Actual, predicted (uncalibrated), and calibrated live weights.

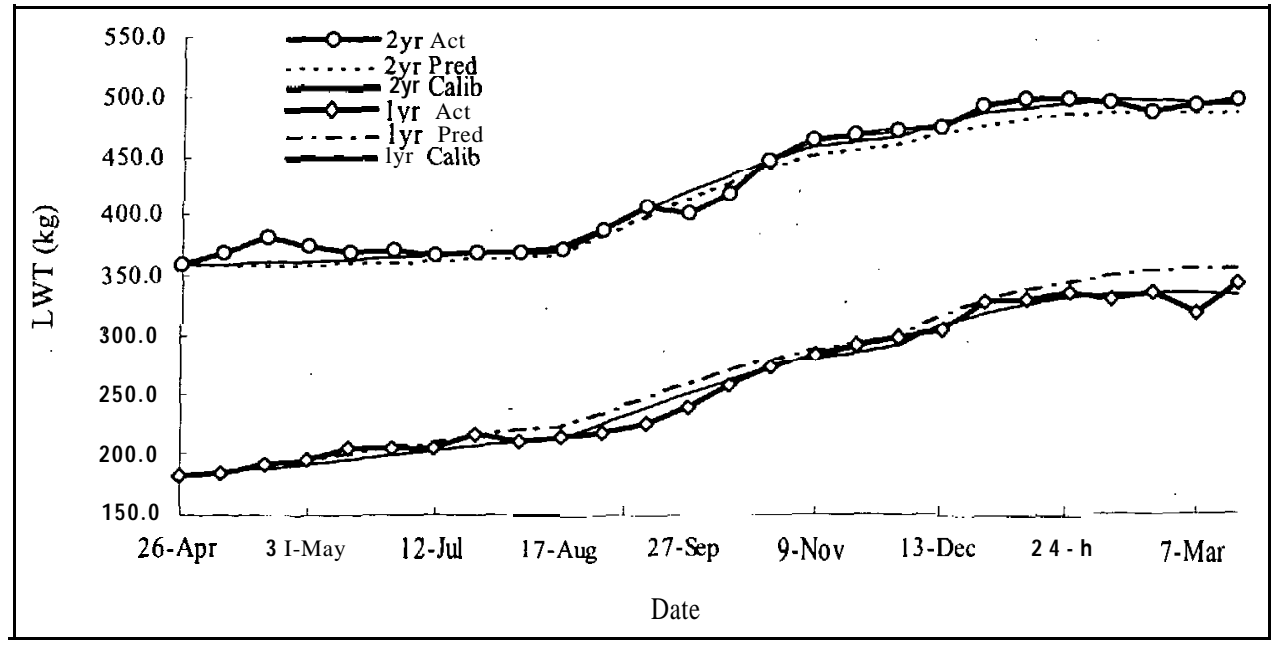


Figure 3 Whatawhata Angus steers, year 2.

Actual, predicted (uncalibrated), and calibrated live weights.

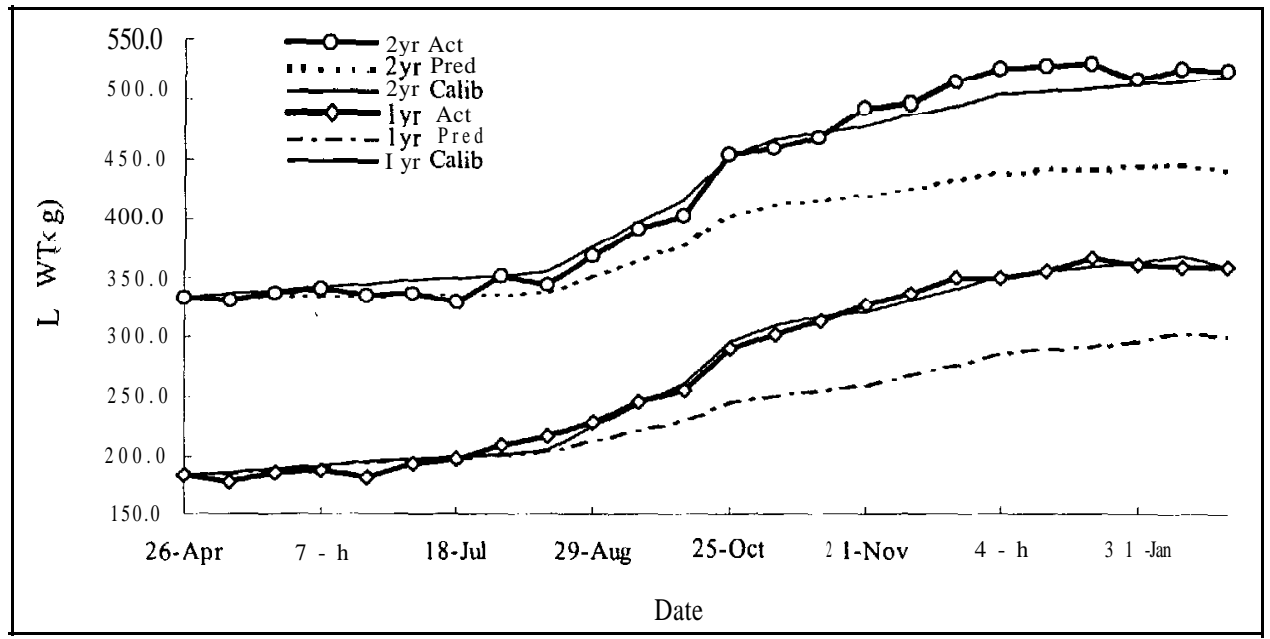

\section{Discussion}

The model, using the base parameter values, predicted well across trials with two widely contrasting genotypes and sex of finishing cattle. However, the fit for Angus steers in the second year was not so good. The calibration facility allowed the model to improve its prediction performance by allowing increased intakes on low pasture masses. The model's performance predicting across breeds gives confidence in the mature weight scaling of maintenance. However, the fact that the model fitted well to Angus data with an intake that was generally lower than actually measured (Table 1), suggests that maintenance efficiency is slightly overestimated for Angus cattle. The suggestion that maintenance efficiency is higher in Angus than in Friesians contradicts evidence of Jenkins \& Ferrill (1983), and indicates the need for futher study of the concept of maintenance in growing animals. Prediction of intake from pasture disappearance is another factor influencing this result. lntake estimates for the Whatawhata trial were consistently higher than those of Angus steers on a feedlot (Muir, pers. comm.). Pasture loss due to treading could be partially responsible for the high intake estimates, an aspect under current investigation at Whatawhata. Results from the second year of the Whatawhata trial indicate a deviation in the predicted results from actual and calibrated starting in the spring period (Figure 3). We suspect the Angus intake model is not giving the levels of intake recorded at low pre-grazing masses in spring.

Another element influencing the performance of the model is evidence of seasonality in maintenance requirements in New Zealand data (e.g., Clark \&
Brougham 1979). This could explain differences in efficiency of cattle at different times of the year i.e. they are more efficient in spring, This seasonality is evident in the Whatawhata data, and this factor has been incorporated into BoVision. Based on our results, we are confident BoVision will thus give more realistic predictions of animal performance than feed tables, owing to the incorporation of this mechanism.

A wide range of trials and breeds were used to fit parameter values used in the model. A consequence of using a mean set of parameters is that the model will fit some data sets well, while others will result in poorer fits. An advantage of BoVision's calibration facility when used on a particular farm, is that it allows tuning to reflect the circumstances of the farm, by adjusting parameters associated with intake efficiency of cattle at different pasture masses. It also estimates the amount of pasture growth required to support past levels of beef production, as supplied to the model by the user.

\section{Conclusions}

BoVision is available for farmers and consultants to use to assist beef finishing policy and tactical decision making. We are confident, based on these results, that BoVision is sufficiently accurate to be useful for decision support. In particular, the calibration feature ensures BoVision can be tuned to reflect conditions on a given farm.

\section{ACKNOWLEDGMENTS}

This work was supported by funding from the Meat Research and Development Corporation. Thanks are 
due to the following beef farmers who helped in the development of BoVision. Peter Clarkin (Hamilton), Mike Holdaway (Fielding), Gavin Marshall (Balclutha), Don McKay (Mangatoroto), Mike McMaster (Piopio), Phil Taylor (Te Awamutu), Matt Wall (Featherston), Brent Williams (Fairlie) and Jonathon Thompson (Piopio).

\section{REFERENCES}

Clark, D.A.; Brougham, R.W. 1979. Feed intake of grazing Friesian bulls. Proceedings of New Zealand Society of Animal Production 39: 265-274.

Jenkins, T.G.; Ferrill, C.L. 1983. Nutrient requirements to maintain weight of mature nonlactating nonpregnant cows of four diverse breed types. Journal of animal science 56: 761-770.

Marshall, P.R.; McCall, D.G.; Johns K.L. 1991. Stockpol: A decision support model for livestock farms. Proceedings of the New Zealand Grassland Association 53: 137-140.
McCall, D.G.; Townsley, R.J.; Bircham, J.S.; Sheath, G.W. 1986. The interdependence of animal intake, pre- and post-grazing pasture mass and stocking density. Proceedings of the New Zealand Grassland Association 47: 255-261.

McCall, D.G. 1989. Efficient conversion of pasture to product. Proceedings of a series of field days for beef producers held in May 1992. pp: 19-29.

McCall, D.G. 1992. Profit from finishing. Profitable beefproduction systems: Proceedings of a series of field days for beef producers held in April/May 1989. pp: 28-34.

Parks, J.R. 1982. A theory of feeding and growth of animals. Springer-Verlag, Heidelberg.

Taylor, St C.S. 1980. Genetic size-scaling in animal growth. Animal production 30: 161-1 65.

Weeda, W.C.; During, C. 1975. Sprinkler irrigation of pasture for dairy beef bulls. Proceedings of the New Zealand Grassland Association 36: 54-6 1. 